\title{
A tool for tracing emergency vehicles during evacuation
}

\author{
A. Polimeni, A. Quattrone \& A. Vitetta \\ Mediterranea University of Reggio Calabria, Italy
}

\begin{abstract}
The topic discussed in this paper concerns the design of the best routes for emergency vehicles to save weak users. The design problem is formalized in order to allow the emergency vehicles (ambulances) to rescue all weak users in the shortest time. In particular, in this paper a hardware-software tool that can be used to collect real-time data for the implementation of the proposed models is analyzed. The tool is designed to identify the paths (mapping the vehicle position at fixed time intervals) and to register the vehicle stops at the weak user's location.
\end{abstract}

Keywords: evacuation, path design, vehicle routing problem, emergency conditions.

\section{Introduction}

Evacuation procedures are used when faced with catastrophic events, both natural (floods, hurricanes, wildfires, and so on) and man-made (nuclear and chemical accidents, terrorist attacks and so on).

In emergency management [1] two phases can be identified [2]: a planning phase and an operative phase. The first one concerns the operations planning (protocols) to be implemented in an emergency in the case of evacuating the population, the second one concerns the application of the procedures provided in the planning phase and their possible modifications.

This work is a part of the SICURO research project [3] carried out by the LAST-Laboratory for Transport Systems Analysis of the Mediterranean University of Reggio Calabria. The objective of the SICURO project is the development of models and guidelines for evacuation demand simulation [4-6], supply and demand-supply interaction simulation [7-9], supporting path design 
for emergency vehicles [10-12], pedestrians outflow in the buildings simulation [13-15] and supporting urban transport planning in emergency conditions [16-18].

A classical approach is the solution of a vehicle routing problem: noting the user positions, the ambulance routes are designed to reach all users in the minimal amount of time. The time depends on the network characteristics; in emergency conditions two cases can be considered [10-12]: the network has a mixed use (i.e., all vehicles can use it without restrictions), or the network has some reserved links (i.e. can only be used by emergency vehicles). A procedure for network design [19] can also be considered for optimizing the movement of emergency vehicles (i.e., with a signal priority system).

The problem of an emergency vehicle that has to pick up users at fixed points of the network and to bring them to a refuge area can be schematized in three steps (in section 2 the argument is detailed):

- system performances estimation, which gives the output of the link flow and cost;

- one-to-one problem solution, which gives the output of the shortest path (or in general the multiple paths with their probability between each origindestination pair);

- many-to-one problem solution, which gives the output of the optimal routes for emergency vehicles.

The main aim of this paper is the design of optimal routes for an ambulance to rescue some weak users (a weak user is a person lacking in bodily strength or healthy vigour, such as from age or sickness). The design of optimal routes requires knowledge of the cost of the links and it is necessary to define a cost function. For this purpose the paths taken by emergency vehicles are traced, taking the costs of certain links of the network: the estimation (specification, calibration and validation) of a cost function allows one to establish the value of the cost on each network link in relation to the time slice during the day. The tracing of emergency vehicle paths required the design and implementation of appropriate tools (hardware and software).

The paper is structured as follows. In section 2, some steps are proposed and discussed for designing the routes for emergency vehicles. In section 3 a hardware-software tool that can be used for data collection in real time is described. In section 4 some conclusive considerations are reported.

\section{Models}

To identify the optimal routes for an emergency vehicle, three steps can be followed:

- $\quad$ system performance estimation, which can be achieved through one, or a combination, of the following: Traffic Assignment (TA) (static or dynamic), Real-time System Monitoring (RSM) or Reverse Assignment (RA) [20];

- One-to-One Problem (OOP) solution, which consists, given the costs on the network obtained by the previous step, in generating alternative paths for each origin-destination pair; 
- many-to-one problem (Vehicle Routing Problem-VRP) solution, which consists, given the optimal paths between every origin-destination pair obtained by solving the OOP, in the solution of a VRP formulated as a classic optimization problem whose objective is to calculate the best combination of one-to-one paths in order to visit a certain number of network nodes in succession.

\subsection{System performance estimation}

To calculate the link flows and costs, three methods could be used: TA, RSM and/or RA.

The TA method simulates the demand-supply interaction to determine system performance (flows and costs). Two approaches are possible: User Equilibrium (UE) or Dynamic Process (DP) [7, 8, 21].

RSM allows us to obtain the traffic flow data using monitoring techniques and can be obtained with measurement at fixed points in the network (with traditional measurement systems as loop detectors and image processing [22] or floating cars [23] in the network (individual cars, taxis, transit system vehicles). RSM costs and flows are usually made for a subset of the network links.

RA models [20] have in input link flows and costs and give in output the link cost parameters of the cost-flow functions used in the supply model and the value (number of trips) and/or the model parameters of the demand model. Starting from the observed costs and flows (i.e. provided by RSM), RA models provide the demand value and/or parameter and/or the link cost parameters of the cost-flow functions used in the supply model.

\subsection{One-to-one problem}

To solve the OOP (shortest path) exact or heuristic algorithms [24, 25] can be used. Considering the ordinary condition, in literature there are several applications of these procedures also for ambulances dispatching [26]. Furthermore, there are several software for the detection of shortest paths [12]. For an extended review of these topics refer to [10].

In this paper, to solve the OOP, a probabilistic approach is adopted. In this approach the path cost is considered as a random variable resulting from the user's perception.

The probability of considering a path in vehicle routing $\mathrm{p}_{\mathrm{n}}(\mathrm{k})$ can be calculated as the sum, on all the sub-sets $\Gamma_{\mathrm{i}}$ which contain the alternative $\mathrm{k}$, of the product between the probability $\mathrm{p}_{\mathrm{n}}\left(\mathrm{k} / \Gamma_{\mathrm{i}}^{\mathrm{n}}\right)$ of perceiving the sub-set $\Gamma_{\mathrm{i}}^{\mathrm{n}}$ and the conditional probability $\mathrm{p}_{\mathrm{n}}\left(\mathrm{k} / \Gamma_{\mathrm{i}}^{\mathrm{n}}\right)$ of considering path $\mathrm{k}$ given the choice set $\Gamma_{\mathrm{i}}^{\mathrm{n}}$ [27]:

$$
\mathrm{p}_{\mathrm{n}}(\mathrm{k})=\sum_{\mathrm{i}} \mathrm{p}_{\mathrm{n}}\left(\Gamma_{\mathrm{i}}^{\mathrm{n}}\right) \cdot \mathrm{p}_{\mathrm{n}}\left(\mathrm{k} / \Gamma_{\mathrm{i}}^{\mathrm{n}}\right)
$$

\subsection{Vehicle routing problem}

Concerning the many-to-one approach, the VRP is used to define a choice set that consists of several paths, each of which optimizes an objective function and 
connects one origin (refuge area) to many destinations (weak user residences). The VRP consists in designing optimal routes from a fixed point (i.e. the ambulance depot) to a set of users, in general subject to various constraints. The VRP was introduced to optimize the freight vehicle routes, and in this topic a lot of works ([28, 29] for extended references) were published. In some works [26] the vehicle routing problem was proposed for emergency vehicles in ordinary conditions, in other [30-32] the VRP was proposed to optimize the source allocation in a post disaster scenario (i.e. to allocate medical supply or emergency vehicles). In [10-12] a VRP to optimize the ambulance routes in a pre disaster scenario (when the disaster has been notified but not yet happened [3]) was proposed.

For the problem formulation refer to [12].

\section{Tool}

In this section how the proposed procedures were tested is described.

Application to a real case was done to simulate an experience of evacuation planning for weak users due to a hypothetical forthcoming disaster executed in the within of SICURO project in the experimental test site of Melito Porto Salvo (Reggio Calabria, Italy).

Real case application was designed to detect the paths and stops of an ambulance to rescue some users.

The instrumentation consisted of a PDA equipped with GPS tracing (figure 1) and software that mapped the points (to identify the paths) at fixed time intervals (in this case 10 seconds); the stops were identified interactively by an operator; by using the PDA other data were obtained to determine characteristics of the intervention (number of users, user location, and so on).

The arrival time at the user residence was indicated by the operator. The start was derived by analyzing the points that spatially coincide with the stop and assuming that the departure moment is the instant of observation of the last of

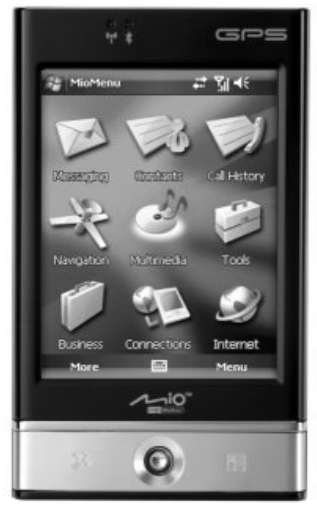

Figure 1: $\quad$ The PDA used. 
these points. The stop duration (operation time) was calculated accordingly with the measures.

The used software interfaces with the operator through two main forms (figure $2 \mathrm{a} / \mathrm{b}$ ). The first one allows one to record the start/return at the refuge area (to take the paths) and to indicate the positions where the weak users are located. The second one, which is accessed from the first, contains the questions text provided by the analyst. The software is managed by an input file (figure 4) in which parameters (i.e. log interval) and questions type and text are supplied.

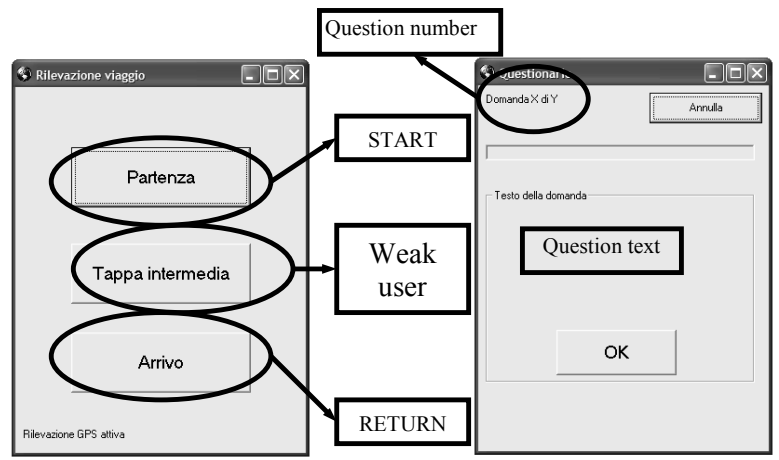

(a)

(b)

Figure 2: $\quad$ The software forms.

10
\#QUESTIONNAIRE
2
\# 1
$\mathrm{~L}$
The weak user is on the
floor number...
\# 2
$\mathrm{M}$
Need for special
equipment at this stop
2
YES
NO
\#PARTENZA
00
\# TAPPA INTERMEDIA
11
\#ARRIVO
00

$/ / \log$ interval (seconds)

// Total question number

// first question

// L-type question

// L-type question text

// second question

// M-type question

// M-type question text

// provided answers number

// provided answers

// there is no question associated with the command button PARTENZA

// the first and the second demand are associated with the command button TAPPA INTERMEDIA

// there is no question associated with the command button ARRIVO

Figure 3: An example of an input file. 


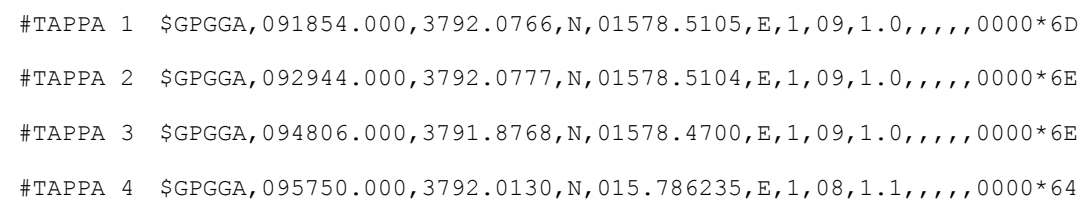

(a)

\begin{tabular}{|c|c|c|c|c|c|c|c|c|}
\hline UTC & Latitude & & Longitud & & $\begin{array}{c}\text { Fix } \\
\text { quality }\end{array}$ & $\begin{array}{c}\text { Number of } \\
\text { satellites } \\
\text { being } \\
\text { tracked }\end{array}$ & $\begin{array}{c}\text { Horizontal } \\
\text { dilution } \\
\text { of } \\
\text { position }\end{array}$ & $\begin{array}{c}\text { checksum } \\
\text { data }\end{array}$ \\
\hline 90152 & 37.92237 & $\mathrm{~N}$ & 15.77756 & $\mathrm{E}$ & 1 & 9 & 0.10 & $\star 71$ \\
\hline 90202 & 37.92235 & $\mathrm{~N}$ & 15.77845 & $\mathrm{E}$ & 1 & 9 & 0.10 & $\star 7 \mathrm{~B}$ \\
\hline 90212 & 37.92220 & $\mathrm{~N}$ & 15.77960 & $E$ & 1 & 10 & 0.09 & $\star 7 \mathrm{E}$ \\
\hline 90222 & 37.92191 & $\mathrm{~N}$ & 15.78076 & $\mathrm{E}$ & 1 & 10 & 0.09 & $\star 77$ \\
\hline 90232 & 37.92180 & $\mathrm{~N}$ & 15.78135 & $\mathrm{E}$ & 1 & 10 & 0.09 & *70 \\
\hline 90242 & 37.92146 & $\mathrm{~N}$ & 15.78156 & $\mathrm{E}$ & 1 & 10 & 0.09 & $\star 7 \mathrm{~A}$ \\
\hline 90252 & 37.92123 & $\mathrm{~N}$ & 15.78153 & $E$ & 1 & 10 & 0.09 & $\star 7 \mathrm{~A}$ \\
\hline
\end{tabular}

(b)

Figure 4: (a) An example of an output file: stops. (b) An example of an output file: paths.

There are two question types: L-type questions are open questions (that is, the operator must write the answer), M-type questions, are multiple-choice questions (that is, the answers were provided by the analyst and the operator chooses one). The questions are activated when the operator pushes a command button provided in the first form.

In figure 4(a) some data related to the stops are reported; in figure 4(b) some data related to the paths are reported.

\section{Conclusion}

In this paper a design method for emergency vehicles routes, to safe weak users, lacking in bodily strength or healthy vigour (as from age or sickness) was discussed. The design problem introduced allows to the emergency vehicles (ambulances) to rescue all weak users in the shortest time. A hardware-software tool that can be used to collect real-time data used for the implementation of the proposed models is analyzed. This tool helps to collect real-time some data necessary for the development of the proposed model (e.g., weak user characteristics), moreover allows a real time monitoring of the routes and stops for emergency vehicles.

In the future the models for interaction between simulation and design approach will be developed. 


\section{References}

[1] Russo F. \& Vitetta A., Risk evaluation in a transportation system. International Journal of Sustainable Development and Planning, 1 (2), pp. 170-191, 2006.

[2] Vitetta A., Quattrone A. \& Polimeni A., Safety of users in road evacuation: Modelling and DSS for paths design of emergency vehicles. Proc. of Sustainable Development and Planning IV, vol.1, Brebbia C. A. (ed.), WIT Press, Southampton, pp. 485-495, 2009.

[3] Russo F. \& Vitetta A., Safety of users in road evacuation: General methodology and main results. Proc. of Urban Transport XIII, Urban Transport and the Environment in the 21st century, Brebbia C. A. (ed.), WIT Press, Southampton, pp. 763-772, 2007.

[4] Russo F. \& Chilà G., Safety of users in road evacuation: demand models. Proc. of Urban Transport XIII, Urban Transport and the Environment in the 21st century, Brebbia C. A. (ed.), WIT Press, Southampton, pp. 773$782,2007$.

[5] Russo F. \& Chilà G., Safety of users in road evacuation: RP vs. SP surveys in demand analysis. Proc. of Urban Transport XIV, Urban Transport and the Environment in the 21st century, Brebbia C. A. (ed.), WIT Press, Southampton, pp. 703-713, 2008.

[6] Russo F. \& Chilà G., Safety of users in road evacuation: Modelling and DSS for demand. Proc. of Sustainable Development and Planning IV, vol.1, Brebbia C. A. (ed.), WIT Press, Southampton, pp. 465-474, 2009.

[7] Vitetta A., Musolino G. \& Marcianò F.A., Safety of users in road evacuation: Supply and demand-supply interaction models for users. Proc. of Urban Transport XIII, Urban Transport and the Environment in the 21st century, Brebbia C. A. (ed.), WIT Press, Southampton, pp. 783-792, 2007.

[8] Vitetta A., Musolino G. \& Marcianò F. A., Safety of users in road evacuation: calibration of cost functions and simulation. Proc. of Urban Transport XIV, Urban Transport and the Environment in the 21st century, Brebbia C. A. (ed.), WIT Press, Southampton, pp. 715-725, 2008.

[9] Vitetta A., Musolino G. \& Marcianò F.A., Safety of users in road evacuation: Modelling and DSS for transport supply and supply-demand interaction. Proc. of Sustainable Development and Planning IV, vol.1, Brebbia C. A. (ed.), WIT Press, Southampton, pp. 475-484, 2009.

[10] Vitetta A., Quattrone A. \& Polimeni A., Safety of users in road evacuation: design of path choice models for emergency vehicles. Proc. of Urban Transport XIII, Urban Transport and the Environment in the 21st century, Brebbia C. A. (ed.), WIT Press, Southampton, pp. 803-812, 2007.

[11] Vitetta A., Quattrone A. \& Polimeni A., Safety of users in road evacuation: algorithms for path design of emergency vehicles, Proc. of Urban Transport XIV, Urban Transport and the Environment in the 21st century, Brebbia C. A. (ed.), WIT Press, Southampton, pp. 727-737, 2008.

[12] Vitetta A., Quattrone A. \& Polimeni A., Safety of users in road evacuation: Modelling and DSS for paths design of emergency vehicles. Proc. of 
Sustainable Development and Planning IV, vol.1, Brebbia C. A. (ed.), WIT Press, Southampton, pp. 485-495, 2009.

[13] Di Gangi M. \& Velonà P., Safety of users in road evacuation: pedestrian out flow models in a building. Proc. of Urban Transport XIII, Urban Transport and the Environment in the 21st century, Brebbia C. A. (ed.), WIT Press, Southampton, pp. 803-812, 2007.

[14] Di Gangi M., Velonà P. \& Catanzariti A., Safety of users in road evacuation: some enhancement in modelling pedestrian evacuation of a building, Proc. of Urban Transport XIV, Urban Transport and the Environment in the 21 st century, Brebbia C. A. (ed.), WIT Press, Southampton, pp. 739-749, 2008.

[15] Di Gangi M., Safety of users in road evacuation: modelling and DSS for pedestrian outflow. Proc. of Sustainable Development and Planning IV, vol.1, Brebbia C. A. (ed.), WIT Press, Southampton, pp. 497-508, 2009.

[16] Russo F. \& Rindone C., Safety of users in road evacuation: planning internal processes and guidelines. Proc. of Urban Transport XIII, Urban Transport and the Environment in the 21st century, Brebbia C. A. (ed.), WIT Press, Southampton, pp. 825-834, 2007.

[17] Russo F. \& Rindone C., Safety of users in road evacuation: the logical framework approach in evacuation planning. Proc. of Urban Transport $X I V$, Urban Transport and the Environment in the 21st century, Brebbia C. A. (ed.), WIT Press, Southampton, pp. 751-760, 2008.

[18] Russo F. \& Rindone C., Safety of users in road evacuation: Modelling and DSS for LFA in the planning process. Proc. of Sustainable Development and Planning IV, vol.1, Brebbia C. A. (ed.), WIT Press, Southampton, pp. 453-464, 2009.

[19] Cantarella G. E., Pavone G. \& Vitetta A., Heuristics for urban road network design: lane layout and signal settings. European Journal of Operational Research, 175, pp. 1682-1695, 2006.

[20] Russo F. \& Vitetta A., Reverse assignment: Updating demand and calibrating cost jointly from traffic counts and time measurements, Proc. of International Symposium on Transportation and Traffic Theory, Maryland University, 2005.

[21] Russo F. \& Vitetta A., An assignment model with modified Logit, which obviates enumeration and overlapping problems. Transportation 30(2), pp. 177-201, 2003.

[22] Hoose N., Computer image processing in traffic engineering, New York: John Wiley \& Sons, Inc., 1991.

[23] Torday A. \& Dumont A.G., Probe vehicles based travel time estimation in urban networks. Proc. of TRISTAN V, 2004.

[24] Russo F., Vitetta, A. \& Quattrone, A., Route choice modelling for freight transport at national level. Proc. of the European Transport Conference, Strasbourg, 2007.

[25] Russo F. \& Vitetta A., La ricerca di percorsi in una rete: Algoritmi di minimo costo ed estensioni, Franco Angeli, Milan, Italy, 2006. 
[26] Yang S., Hamedi M. \& Hagani A., Online Dispatching and Routing Model for Emergency Vehicles with Area Coverage Constraints. Transportation Research Record: Journal of the Transportation Research Board, 1923, 2005.

[27] Manski C., The structure of random utility models. Theory and Decision, 8, pp. 229-254, 1977.

[28] Laporte G., What You Should Know about the Vehicle Routing Problem. Les Cahiers $d u$ GERAD, G-2004-33, HEC Montreal, 2007. (www.gerad.ca/en/publications/cahiers.php)

[29] Gendreau M., Potvin J.Y., Bräysy O., Hasle G. \& Løkketamgen A., Metaheuristics for the vehicle routing problem and its extensions: a categorized bibliography, The vehicle routing problem: latest advances and new challenges (Golden B., Raghavan S., Wasil E., ed.), New York Springer, pp.143-169, 2008.

[30] Liu D., Han J. \& Zhu J., Vehicle routing for medical supplies in large scale emergencies. Proc. of the first international symposium on optimization and systems biology, Beijing, China, August 8-10, 2007.

[31] Jotshi A., Gong Q. \& Batta R., Dispatching and routing of emergency vehicles in disaster mitigation using data fusion. Socio-Economic Planning Sciences, 43, pp. 1-24, 2009.

[32] Mete H.O. \& Zabinsky Z.B., Stochastic optimization of medical supply location and distribution in disaster management. International Journal of Production Economics (Article in press), 2009. 